\title{
ANALISIS KECACATAN PRODUK AIR MINUM DALAM KEMASAN (AMDK) SEBAGAI UPAYA PERBAIKAN KUALITAS DENGAN METODE DMAIC
}

\author{
Heri Wibowo dan Emy Khikmawati \\ Jurusan Teknik Industri Universitas Malahayati \\ Jl. Pramuka No 27 Kemiling Bandar Lampung 35153 Indonesia \\ Email : heriwibowo_ti@yahoo.co.id, emy_khikmawati@yahoo.com
}

\begin{abstract}
ABSTRAK
Produsen air minum dalam kemasan (AMDK) mengalami masalah kualitas yaitu dengan terdapatnya produk-produk cacat pada setiap produksi yang belum mencapai zero defect, terutama pada lini produksi kemasan gelas ukuran $240 \mathrm{ml}$ yang paling banyak mengalami kecacatan produk. Six Sigma dapat didefinisikan sebagai suatu metodologi yang menyediakan alat-alat untuk peningkatan proses bisnis dengan tujuan menurunkan variasi proses dan meningkatkan kualitas produk dengan menggunakan pendekatan DMAIC (define, measure, analyze, improve dan control). Dari hasil pengukuran data yang diperoleh bahwa untuk critical to quality (CTQ) kunci berdasarkan diagram pareto, bahwa $80 \%$ kecacatan tertinggi ada pada jenis cacat lid dimana cacat lid ini sendiri terdiri dari bocor lid, pecah lid dan lid miring. Untuk tingkat sigma adalah 4,96 sigma, yang artinya belum mencapai tingkat tingkat six sigma dikarenakan masih tingginya produk cacat. Kemudian dilanjutkan dengan mengalisa penyebab cacat lid dengan menggunakan diagram sebab akibat dan failure mode and effect analysis (FMEA). Dari analisis diagram sebab akibat bahwa faktor penyebab kecacatan berasal dari faktor mesin, material dan manusia. Setelah itu dengan FMEA dapat diketahui bahwa penyebab kegagalan tertinggi adalah seal disc kotor pada saat proses produksi berjalan. Untuk upaya perbaikan dari permasalahan tersebut maka diperlukan pemeriksaan kondisi sealing unit sebelum melakukan proses produksi dan mengamplas sealing unit setiap seminggu sekali pada permukaan yang sudah tidak rata.
\end{abstract}

Kata kunci : Six Sigma, DMAIC

\section{PENDAHULUAN}

Dalam dunia industri, untuk menghasilkan produk berkualitas merupakan keharusan dan fokus utama perusahaan, karena menyangkut persaingan bisnis dengan perusahaan yang lain. Kualitas yang mengacu pada konsumen akan menghasilkan tingkat kepuasan tersendiri bagi konsumen sebagai pemakai atau pengguna produk akhir. Pada umumnya sistem pengendalian kualitas seperti TQM atau yang lain hanya menekankan pada upaya peningkatan terus menerus berdasarkan kesadaran mandiri dari manajemen. Sistem tersebut tidak memberikan solusi yang tepat mengenai terobosan-terobosan atau langkah-langkah yang seharusnya dilakukan untuk menghasilkan peningkatan kualitas secara dramatik menuju tingkat kegagalan nol (zero defect). Six sigma sebagai salah satu metode baru yang paling populer merupakan salah satu alternatif dalam prinsip-prinsip pengendalian kualitas yang merupakan terobosan dalam bidang manajemen kualitas (Gasperzs, 2011). Six sigma dapat dijadikan ukuran kinerja sistem industri yang memungkinkan perusahaan melakukan peningkatan yang luar biasa dengan terobosan strategi yang aktual. Six sigma juga dapat dipandang sebagai pengendalian proses industri yang berfokus pada pelanggan dengan memerhatikan kemampuan proses. Pencapaian six sigma hanya terdapat 3,4 cacat per sejuta kesempatan. Semakin tinggi target sigma yang dicapai maka kinerja sistem industri semakin membaik (Muhaemin, 2012).

\section{KAJIAN PUSTAKA}

Dalam perusahaan pabrik, istilah kualitas diartikan sebagai faktor-faktor yang terdapat dalam suatu barang/hasil yang menyebabkan barang/hasil tersebut sesuai dengan tujuan untuk apa barang atau hasil dimaksudkan atau dibutuhkan (Assauri, 1993: 267). Kualitas merupakan salah satu tujuan penting sebagian besar organisasi. Mengingat mutu ini menyangkut organisasi secara keseluruhan, maka fungsi operasi dibebani tanggung 
jawab untuk menghasilkan mutu bagi pelanggan. Tanggung jawab ini bisa dilakukan hanya melalui menajemen serta pengendalian mutu yang benar pada semua tahap operasi (Schroeder,1995:167). Menurut W. Edwards Deming menjelaskan bahwa kualitas merupakan perbaikan secara berkesinambungan pada sebuah sistem yang stabil (Sumayang, 1991: 267). Menurut American Society for Quality Control, kualitas adalah totalitas bentuk dan karakteristik barang atau jasa yang menunjukkan kemampuannya untuk memuaskan kebutuhan-kebutuhan yang tampak jelas maupun yang tersembunyi (Render, and Heizer. 2001: 92). Sedangkan Kualitas menurut Feigenbaum (1996:7) merupakan keseluruhan karakteristik produk dan jasa dari pemasaran, rekasaya, pembikinan, dan pemeliharaan yang membuat produk dan jasa yang digunakan memenuhi harapan-harapan pelanggan. Six Sigma adalah suatu filosofi manajamen yang terkenal di seluruh dunia. Tujuan dari Six Sigma adalah membuat kinerja suatu organisasi lebih efektif dan efesien. Saat ini metode penjagaan kualitas yang sedang berkembang adalah Six Sigma. Six Sigma adalah sebuah metode perbaikan kualitas berbasis stastistik yang memerlukan disiplin tinggi dan dilakukan secara komprehensif yang mengeleminasi sumber masalah utama dengan pendekatan DMAIC (Define-Measure-Analize-ImproveControl). Six Sigma merupakan sistem yang komprehensif dan fleksibel untuk mencapai, mempertahankan, dan memaksimalkan sukses bisnis. Six sigma secara unik dikendalikan oleh pemahaman yang kuat terhadap kebutuhan pelanggan, pemakaian yang disiplin terhadap fakta, data dan analisis statistik, dan perhatian yang cermat untuk mengelola, memperbaiki dan menanamkan kembali proses bisnis (Peter S. Pande dkk, 2003). Menurut Setiawan, Six sigma juga merupakan suatu cara untuk mengukur kemungkinan perusahaan dapat membuat atau menghasilkan berbagai jumlah unit yang ditentukan dari suatu produk atau jasa dengan jumlah cacat nol (zero defects ). Six Sigma dapat didefinisikan sebagai suatu metodologi yang menyediakan alat-alat untuk peningkatan proses bisnis dengan tujuan menurunkan variasi proses dan meningkatkan kualitas produk. Pendekatan Six sigma merupakan sekumpulan konsep dan praktik yang berfokus pada penurunan variasi proses dan penurunan kegagalan atau kecacatan produk (Gaspersz, 2011: 91). Menurut Evans dkk (2008), Six Sigma merupakan metode peningkatan proses bisnis yang bertujuan untuk menemukan dan mengurangi faktor-faktor penyebab kecacatan dan kesalahan, mengurangi siklus dan biaya operasi, meningkatkan produktivitas, memenuhi kebutuhan pelanggan dengan cepat, mencapai tingkat pendayagunaan aset yang lebih tinggi, serta mendapatkan imbal hasil atas investasi yang lebih baik dari segi produksi maupun pelayanan. Dengan demikian Six Sigma dapat dijadikan ukuran target kinerja proses produksi tentang bagaimana baiknya suatu proses transaksi produk antara industri dan pelanggan. Semakin tinggi target sigma yang dicapai, semakin baik kinerja proses industri. Sehingga 6 sigma otomatis lebih baik dari pada 4 sigma dan 3 sigma. Six Sigma dapat dipandang sebagai pengendalian proses industri berfokus pada pelanggan, melalui penekanan pada kemampuan proses (Gaspersz, 2011: 37).

Tabel 1. Pencapaian Tingkat Sigma

\begin{tabular}{|c|l|}
\hline Tingkat Pencapaian Sigma & DPMO (Defects Per Million Opportunities) \\
\hline 1-Sigma & 691.462 (sangat tidak kompetitif) \\
\hline 2-Sigma & 308.538 (rata-rata industri di Indonesia) \\
\hline 3-Sigma & 66.807 \\
\hline 4-Sigma & 6.210 (rata-rata industri USA) \\
\hline 5-Sigma & 233 (rata-rata industri Jepang) \\
\hline 6-Sigma & 3.4 (industri kelas dunia) \\
\hline
\end{tabular}

Sumber : www.vibizmanagement.com (dalam Chodriyanti, 2009)

Ukuran kegagalan dalam Six Sigma, yang menunjukkan kegagalan per sejuta kesempatan. Target dari Six Sigma adalah 3.4 DPMO, harusnya tidak diinterpretesikan sebagai 3.4 unit output yang cacat dari sejuta unit output yang diproduksi, tetapi 
diinterpretasikan sebagai satu unit produk tunggal terdapat rata-rata kesempatan untuk gagal dari suatu karakteristik CTQ (critical-to-quality) adalah hanya 3.4 bagian dari satu juta kesempatan (DPMO).

$$
\mathrm{DPO}=\frac{\text { Jumlah Cacat }}{\text { Unit Yang Diperiksa X Peluang Cacat }}
$$

$\mathrm{DPMO}=\mathrm{DPO} \times 1000000$

\section{METODOLOGI PENELITIAN}

Obyek penelitian yang diteliti adalah air minum dalam kemasan cup $240 \mathrm{ml}$. Tahapan dan metodologi penelitian adalah pengumpulan data yang kemudian dilakukan pengolahan data dengan metode DMAIC, antara lain tahap Define, melakukan pemetaan proses, identifikasi karakteristik produk akhir dan penentuan CTQ ; tahap Measure, melakukan identifikasi proses dengan peta kendali $\mathrm{P}$ dan pengukuran level sigma ; tahap Analize, melakukan analisa penyebab masalah dengan diagram sebab akibat dan FMEA ; tahap Improve, melakukan usulan perbaikan berdasarkan penyebab masalah ; tahap Control, melakukan usulan pengendalian berdasarkan tahap Improve sebelumnya.

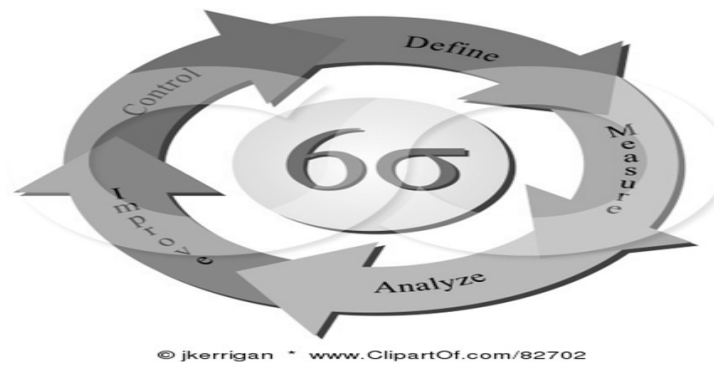

Gambar 1. Metodologi Six Sigma

\section{HASIL DAN PEMBAHASAN}

Tabel 2. Data Tingkat Kecacatan Produk Air Minum Dalam Kemasan Cup 240 ml

\begin{tabular}{|c|c|c|c|c|c|c|c|}
\hline Pengamatan & $\begin{array}{c}\text { Cacat } \\
\text { Cup }\end{array}$ & $\begin{array}{c}\text { Cacat } \\
\text { Lid }\end{array}$ & $\begin{array}{c}\text { Cacat } \\
\text { Volume }\end{array}$ & $\begin{array}{c}\text { Cacat } \\
\text { Mesin }\end{array}$ & $\begin{array}{c}\text { Kotor } \\
\text { Air }\end{array}$ & $\begin{array}{c}\text { Jumlah } \\
\text { Cacat }\end{array}$ & $\begin{array}{c}\text { Jumlah } \\
\text { Produksi }\end{array}$ \\
\hline 1 & 0 & 0 & 0 & 0 & 0 & 0 & 0 \\
\hline 2 & 64 & 867 & 76 & 12 & 72 & 1091 & 841728 \\
\hline 3 & 30 & 1006 & 20 & 19 & 64 & 1139 & 826704 \\
\hline 4 & 54 & 922 & 29 & 15 & 72 & 1092 & 930816 \\
\hline 5 & 22 & 1024 & 65 & 17 & 75 & 1203 & 843648 \\
\hline 6 & 0 & 0 & 0 & 0 & 0 & 0 & 0 \\
\hline 7 & 25 & 966 & 62 & 15 & 68 & 1136 & 793920 \\
\hline 8 & 49 & 1846 & 74 & 18 & 101 & 2088 & 1336896 \\
\hline 9 & 41 & 1518 & 113 & 29 & 498 & 2199 & 1198032 \\
\hline 10 & 50 & 1785 & 98 & 23 & 200 & 2156 & 1370784 \\
\hline 11 & 52 & 401 & 104 & 21 & 209 & 787 & 691344 \\
\hline 12 & 31 & 475 & 44 & 16 & 49 & 615 & 352656 \\
\hline 13 & 0 & 0 & 0 & 0 & 0 & 0 & 0 \\
\hline 14 & 36 & 765 & 36 & 13 & 71 & 921 & 1097616 \\
\hline 15 & 43 & 830 & 43 & 27 & 60 & 1003 & 750912 \\
\hline 16 & 35 & 902 & 63 & 17 & 77 & 1094 & 783936 \\
\hline 17 & 42 & 1001 & 57 & 15 & 97 & 1212 & 1179552 \\
\hline
\end{tabular}




\begin{tabular}{|c|c|c|c|c|c|c|c|}
18 & 32 & 639 & 51 & 10 & 70 & 802 & 698352 \\
\hline 19 & 0 & 0 & 0 & 0 & 0 & 0 & 0 \\
\hline 20 & 0 & 0 & 0 & 0 & 0 & 0 & 0 \\
\hline 21 & 46 & 797 & 12 & 11 & 55 & 921 & 676416 \\
\hline 22 & 28 & 833 & 28 & 32 & 101 & 1022 & 875280 \\
\hline 23 & 32 & 964 & 36 & 25 & 67 & 1124 & 861408 \\
\hline 24 & 0 & 0 & 0 & 0 & 0 & 0 & 0 \\
\hline 25 & 43 & 1008 & 39 & 59 & 94 & 1243 & 760704 \\
\hline 26 & 30 & 480 & 24 & 10 & 29 & 573 & 434544 \\
\hline 27 & 0 & 0 & 0 & 0 & 0 & 0 & 0 \\
\hline 28 & 104 & 1045 & 25 & 14 & 84 & 1272 & 798768 \\
\hline 29 & 34 & 791 & 18 & 14 & 145 & 1002 & 814224 \\
\hline 30 & 37 & 941 & 22 & 17 & 80 & 1097 & 889344 \\
\hline 31 & 39 & 1029 & 19 & 13 & 84 & 1184 & 914160 \\
\hline Total & 999 & 22835 & 1158 & 462 & 2522 & 27976 & 20721744 \\
\hline
\end{tabular}

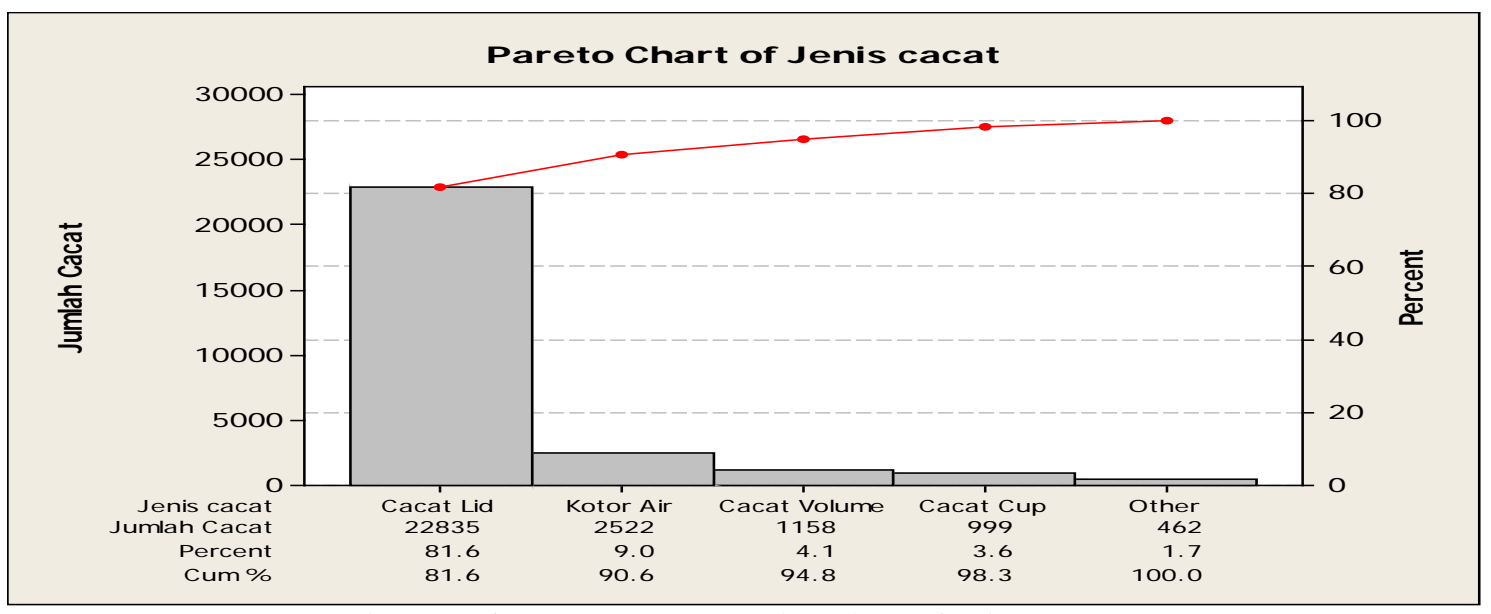

Gambar 2. Diagram Pareto Berdasarkan Tingkat Kecacatan

Berdasarkan diagram pareto diatas dapat dilihat bahwa 80\% tingkat kecacatan produk air minum dalam kemasan (AMDK) kemasan cup $240 \mathrm{ml}$ terdapat pada jenis cacat lid. Jadi, untuk CTQ kunci perbaikan pada proses produksi air minum dalam kemasan adalah pada jenis cacat lid dimana cacat lid ini terdiri dari cacat lid miring, bocor lid dan pecah lid.

Tabel 3. Perhitungan Batas Kendali dengan Peta $P$

\begin{tabular}{|c|c|c|c|c|c|c|}
\hline Pengamatan & Jumlah Cacat & Jumlah Produksi & Persentase Kecacatan & CL & UCL & LCL \\
\hline 2 & 1091 & 841728 & 0.0013 & 0.00135 & 0.00469 & -0.00198 \\
\hline 3 & 1139 & 826704 & 0.00138 & 0.00135 & 0.00461 & -0.00191 \\
\hline 4 & 1092 & 930816 & 0.00117 & 0.00135 & 0.00468 & -0.00198 \\
\hline 5 & 1203 & 843648 & 0.00143 & 0.00135 & 0.00453 & -0.00183 \\
\hline 7 & 1136 & 793920 & 0.00143 & 0.00135 & 0.00462 & -0.00192 \\
\hline 8 & 2088 & 1336896 & 0.00156 & 0.00135 & 0.00376 & -0.00106 \\
\hline 9 & 2199 & 1198032 & 0.00184 & 0.00135 & 0.0037 & -0.001 \\
\hline 10 & 2156 & 1370784 & 0.00157 & 0.00135 & 0.00372 & -0.00102 \\
\hline 11 & 787 & 691344 & 0.00114 & 0.00135 & 0.00528 & -0.00258 \\
\hline 12 & 615 & 352656 & 0.00174 & 0.00135 & 0.00579 & -0.00309 \\
\hline 14 & 921 & 1097616 & 0.00084 & 0.00135 & 0.00498 & -0.00228 \\
\hline 15 & 1003 & 750912 & 0.00134 & 0.00135 & 0.00483 & -0.00213 \\
\hline 16 & 1094 & 783936 & 0.0014 & 0.00135 & 0.00468 & -0.00198 \\
\hline
\end{tabular}




\begin{tabular}{|c|c|c|c|c|c|c|}
17 & 1212 & 1179552 & 0.00103 & 0.00135 & 0.00451 & -0.00181 \\
\hline 18 & 802 & 698352 & 0.00115 & 0.00135 & 0.00524 & -0.00254 \\
\hline 21 & 921 & 676416 & 0.00136 & 0.00135 & 0.00498 & -0.00228 \\
\hline 22 & 1022 & 875280 & 0.00117 & 0.00135 & 0.0048 & -0.0021 \\
\hline 23 & 1124 & 861408 & 0.0013 & 0.00135 & 0.00464 & -0.00194 \\
\hline 25 & 1243 & 760704 & 0.00163 & 0.00135 & 0.00447 & -0.00177 \\
\hline 26 & 573 & 434544 & 0.00132 & 0.00135 & 0.00595 & -0.00325 \\
\hline 28 & 1272 & 798768 & 0.00159 & 0.00135 & 0.00444 & -0.00174 \\
\hline 29 & 1002 & 814224 & 0.00123 & 0.00135 & 0.00483 & -0.00213 \\
\hline 30 & 1097 & 889344 & 0.00123 & 0.00135 & 0.00468 & -0.00198 \\
\hline 31 & 1184 & 914160 & 0.0013 & 0.00135 & 0.00455 & -0.00185 \\
\hline Total & 27976 & 20721744 & & & & \\
\hline
\end{tabular}

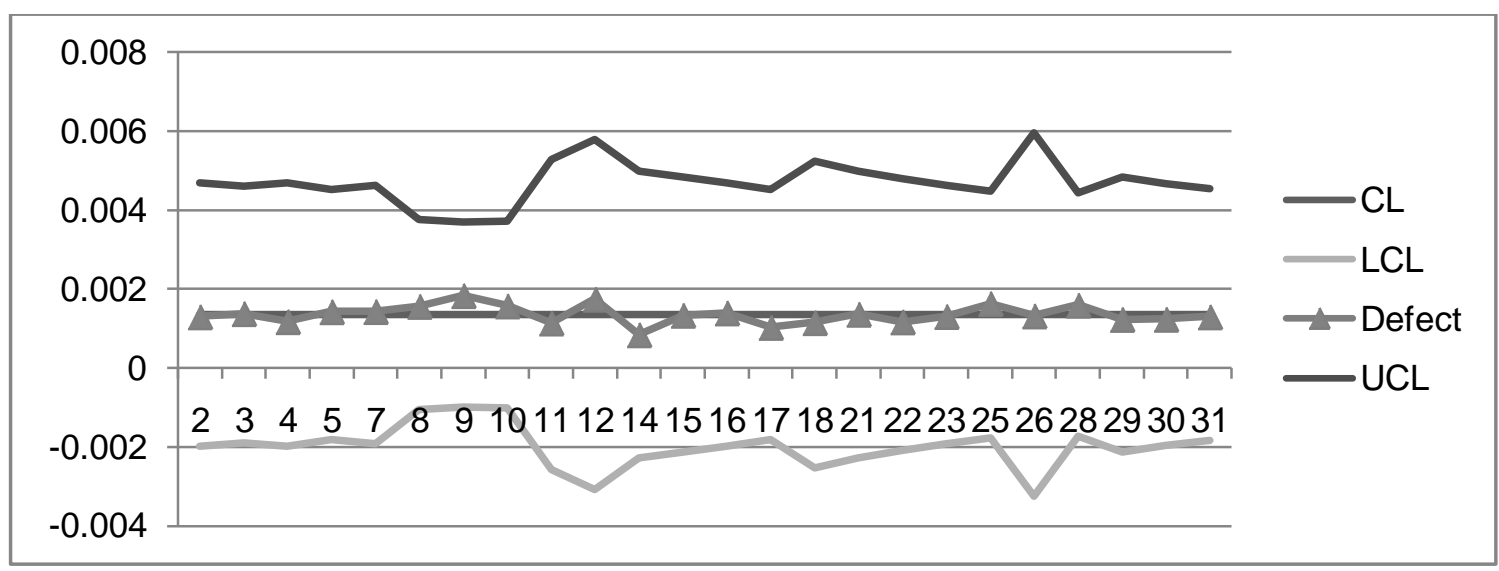

Gambar 3. Grafik Peta Kendali P

Berdasarkan grafik diatas tampak bahwa semua data masih berada pada batas kendali, tetapi belum mencapai tingkat kegagalan nol.

Tabel 4. Hasil Pengukuran Level Sigma

\begin{tabular}{|c|c|c|c|c|c|c|c|}
\hline Pengamatan & Jumlah Cacat & Jumlah Produksi & OP & TOP & DPO & DPMO & Sigma \\
\hline 1 & 0 & 0 & 0 & 0 & 0 & 0 & 0 \\
\hline 2 & 1091 & 841728 & 5 & 4208640 & 0.000259 & 259 & 4.97 \\
\hline 3 & 1139 & 826704 & 5 & 4133520 & 0.000284 & 284 & 4.95 \\
\hline 4 & 1092 & 930816 & 5 & 4654080 & 0.000235 & 235 & 5 \\
\hline 5 & 1203 & 843648 & 5 & 4218240 & 0.000285 & 285 & 4.95 \\
\hline 6 & 0 & 0 & & 0 & 0 & 0 & 0 \\
\hline 7 & 1136 & 793920 & 5 & 3969600 & 0.000286 & 286 & 4.94 \\
\hline 8 & 2088 & 1336896 & 5 & 6684480 & 0.000308 & 308 & 4.92 \\
\hline 9 & 2199 & 1198032 & 5 & 5990160 & 0.000367 & 367 & 4.88 \\
\hline 10 & 2156 & 1370784 & 5 & 6853920 & 0.000315 & 315 & 4.92 \\
\hline 11 & 787 & 691344 & 5 & 3456720 & 0.000228 & 228 & 5.01 \\
\hline 12 & 615 & 352656 & 5 & 1763280 & 0.000349 & 349 & 4.89 \\
\hline 13 & 0 & 0 & 0 & 0 & 0 & 0 & 0 \\
\hline 14 & 921 & 1097616 & 5 & 5488080 & 0.000168 & 168 & 5.09 \\
\hline 15 & 1003 & 750912 & 5 & 3754560 & 0.000267 & 267 & 4.96 \\
\hline 16 & 1094 & 783936 & 5 & 3919680 & 0.000279 & 279 & 4.95 \\
\hline 17 & 1212 & 1179552 & 5 & 5897760 & 0.000206 & 206 & 5.03 \\
\hline 18 & 802 & 698352 & 5 & 3491760 & 0.00023 & 229 & 5.00 \\
\hline
\end{tabular}




\begin{tabular}{|c|c|c|c|c|c|c|c|}
\hline 19 & 0 & 0 & 0 & 0 & 0 & 0 & 0 \\
\hline 20 & 0 & 0 & 0 & 0 & 0 & 0 & 0 \\
\hline 21 & 921 & 676416 & 5 & 3382080 & 0.000272 & 272 & 4.96 \\
\hline 22 & 1022 & 875280 & 5 & 4376400 & 0.000234 & 234 & 5.00 \\
\hline 23 & 1124 & 861408 & 5 & 4307040 & 0.000261 & 261 & 4.97 \\
\hline 24 & 0 & 0 & 0 & 0 & 0 & 0 & 0 \\
\hline 25 & 1243 & 760704 & 5 & 3803520 & 0.000327 & 327 & 4.91 \\
\hline 26 & 573 & 434544 & 5 & 2172720 & 0.000264 & 264 & 4.97 \\
\hline 27 & 0 & 0 & 0 & 0 & 0 & 0 & 0 \\
\hline 28 & 1272 & 798768 & 5 & 3993840 & 0.000318 & 318 & 4.92 \\
\hline 29 & 1002 & 814224 & 5 & 4071120 & 0.000246 & 246 & 4.98 \\
\hline 30 & 1097 & 889344 & 5 & 4446720 & 0.000247 & 247 & 4.98 \\
\hline 31 & 1184 & 914160 & 5 & 4570800 & 0.000259 & 259 & 4.97 \\
\hline Total & 27976 & 20721744 & 5 & 103608720 & 0.00027 & 270 & 4.96 \\
\hline
\end{tabular}

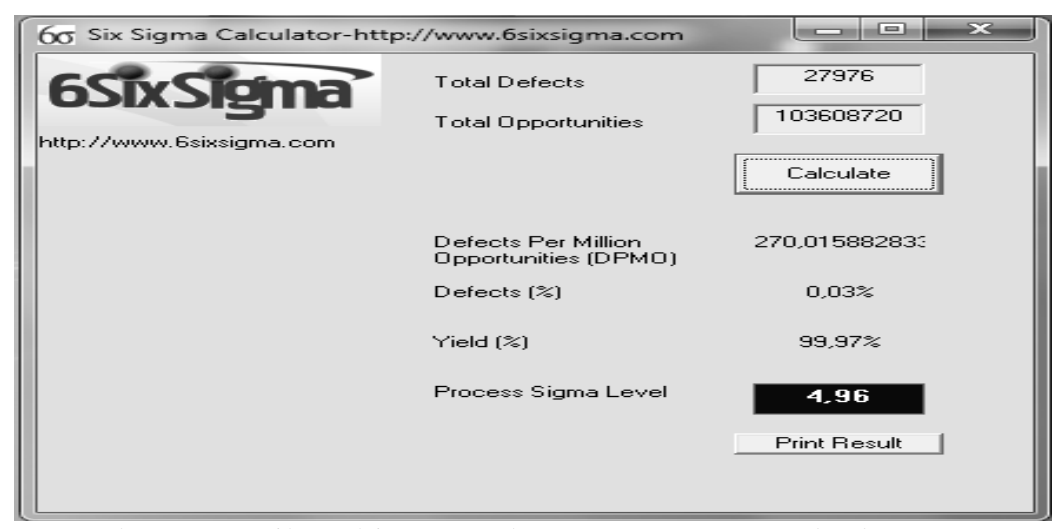

Gambar 4. Hasil Perhitungan dengan Software Calculate Sigma

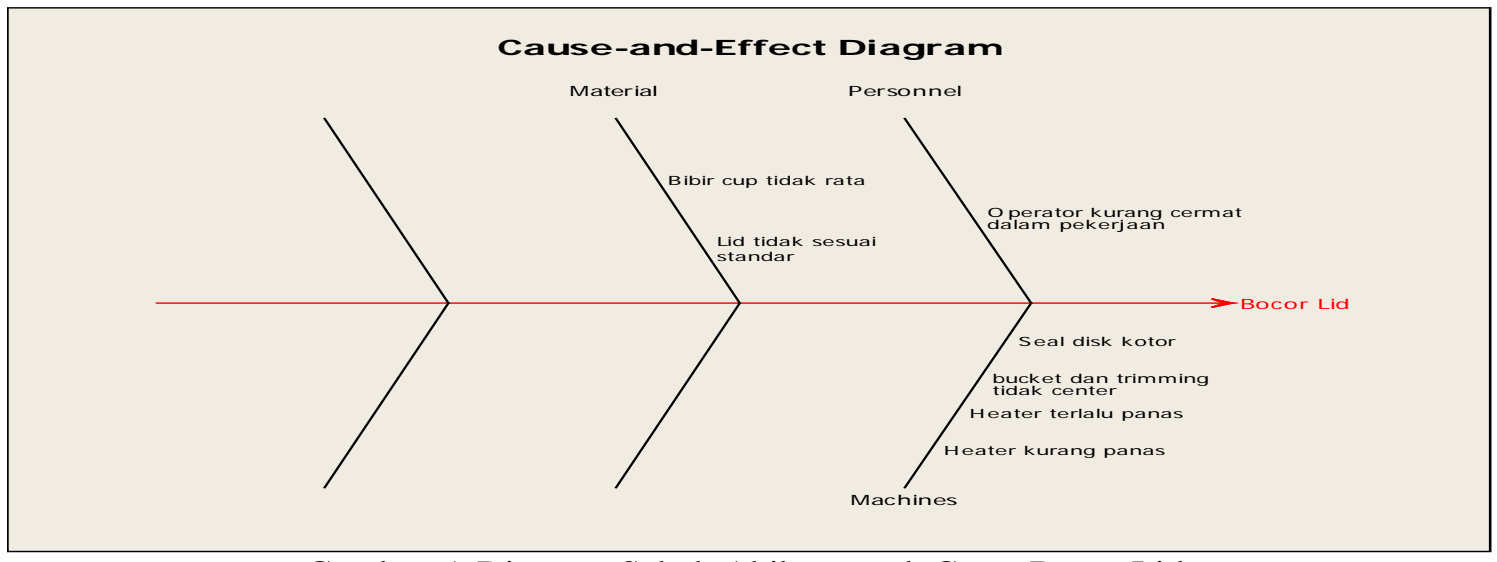

Gambar 5. Diagram Sebab Akibat untuk Cacat Bocor Lid 


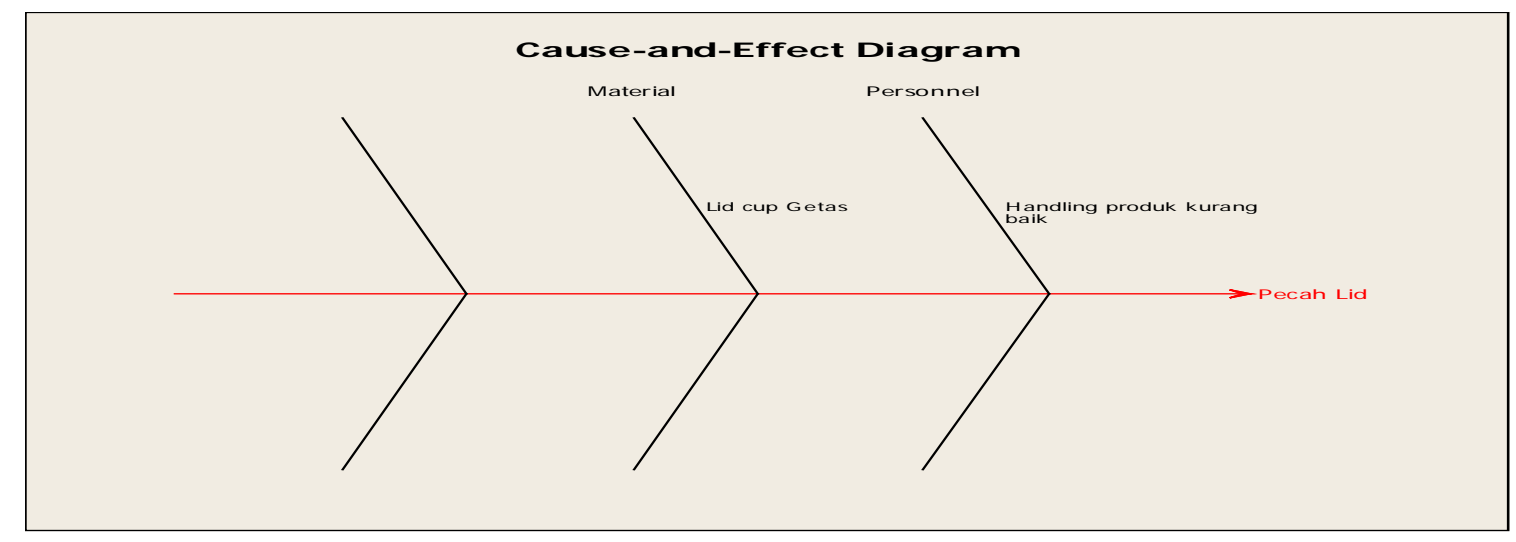

Gambar 6. Diagram Sebab Akibat untuk Cacat Pecah Lid

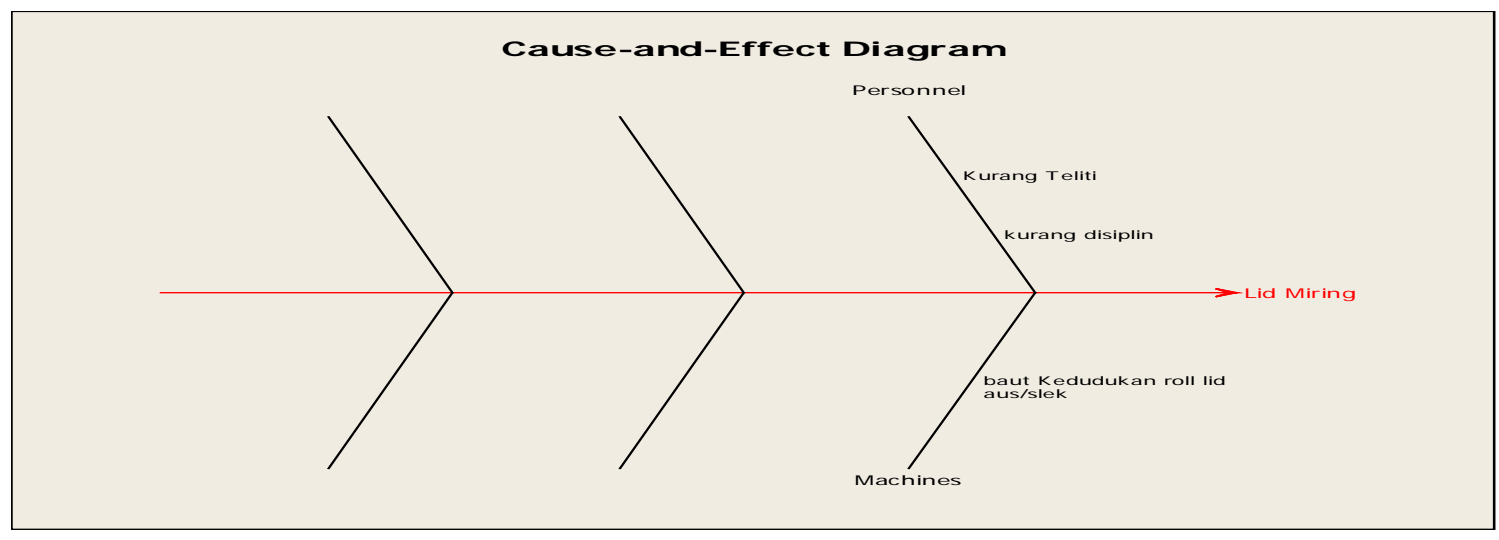

Gambar 7. Diagram Sebab Akibat untuk Cacat Lid Miring

Berdasarkan diagram sebab akibat di atas, diketahui terdapat penyebab terjadinya kecacatan produk. Langkah selanjutnya adalah mengetahui tingkat Severity, Occurence, dan Detection dari faktor penyebab kegagalan dengan menggunakan Failure Mode and Effect Analysis (FMEA) pada Tabel 5 (dalam lampiran). Setelah mengetahui dimana pada tahap sebelumnya telah dilakukan identifikasi sumber-sumber dan akar penyebab dari masalah cacat tersebut, maka langkah selanjutnya adalah menetapkan suatu rencana perbaikan untuk mencegah penyebab-penyebab cacat itu terulang kembali sehingga dapat menurunkan jumlah cacat. Dalam tahap ini juga menggunakan FMEA dalam melakukan usulan rencana perbaikan (recommended action) pada Tabel 6 (dalam lampiran). Setelah dilakukan tindakan perbaikan, maka perlu melakukan tindakan pengendalian terhadap perbaikan-perbaikan tersebut, terutama yang langsung berhubungan dengan proses. Adapun beberapa tindakan pengandalian yang akan diusulkan, sebagai berikut:

1. Melakukan pemeriksaan sebelum proses produksi

2. Perlunya mengadakan bimbingan yang tepat dan melakukan pengawasan yang ketat dan disiplin

3. Pengendalian material diperketat, baik mulai material masuk dari supplier sampai sebelum meterial tersebut masuk pada proses produksi

4. Memantau jalannya produksi dan menganalisa setiap masalah yang ada dilantai produksi oleh semua pekerja yang terlibat dalam masalah tersebut

\section{KESIMPULAN DAN SARAN}

\section{A. Kesimpulan}

Berdasarkan pembahasan di atas, maka dapat diambil kesimpulan sebagai berikut: 
1. Untuk tingkat sigma produksi air minum dalam kemasan adalah 4,96 Sigma. Artinya dalam tahapan tingkat sigma perusahaan belum mencapai tingkat Six Sigma, karena dalam proses produksinya masih mengalami adanya kecacatan produk yang belum mencapai zero defect.

2. Penyebab terjadinya kecacatan produk berdasarkan diagram sebab akibat cacat lid diantaranya :

1) bocor lid : Heater kurang Panas, heater terlalu panas, bucket dengan trimming tidak center, seal disk kotor dan operator kurang cermat.

2) Pecah lid : Lid getas dan handling kurang baik

3) Lid Miring : Kedudukan roll lid goyang dan operator kurang teliti

\section{B. Saran}

Adapun saran yang dapat diberikan adalah :

1. Diharapkan untuk mencoba melakukan atau mempraktekkan metode pengendalian kualitas Six Sigma dengan DMAIC untuk mengukur hasil pencapaian yang telah dilakukan pada saat produksi.

2. Memberikan arahan kepada pekerja/karyawan sebelum memulai pekerjaan serta melakukan pengecekan menyeluruh pada kesiapan mesin sebelum produksi dimulai dan meningkatkan kesadaran akan mutu pada karyawan,

3. Melakukan penghitungan jumlah kerugian biaya yang di akibatkan produk cacat dalam setiap proses produksi.

4. Untuk penelitian selanjutnya dapat dianalisis lebih mendalam mengenai karekteristik kualitas (CTQ) kunci selain cacat lid beserta faktor penyebabnya dan cara perbaikannya. Perlunya dilakukan evaluasi sebelum dan setelah implementasi Six Sigma di perusahaan sehingga dapat diketahui pengaruhnya.

\section{DAFTAR PUSTAKA}

[1] Assauri, Sofjan. 1993. Manajemen Produksi dan Operasi. Jakarta : Fakultas Ekonomi Universitas Indonesia.

[2] Chodriyanti. 2009. Analisis Kecacatan Produk Merk Aqua Dalam Upaya Perbaikan Kualitas Dengan Metode DMAIC (Studi Kasus pada PT. Tirta Investama, Klaten). Surakarta : Skripsi, Jurusan Teknik Industri Fakultas Teknik Universitas Muhammadiyah Surakarta.

[3] Evans, J. R. and Lindsay,W. M. 2008. The Management and Control of Quality, $7^{\text {th }}$ ed., Mason, OH: South-Western (E.L.)

[4] Feigenbaum. A.V.1996. Kendai Mutu Terpadu. Jakarta. Jakarta: Erlangga.

[5] Gaspersz, Vincent. 2011. Lean Six Sigma For Manufakturing and Service Industries. Bogor : Vincristo Publication.

[6] Muhaemin, Ahmad. 2012. Analisis Pengendalian Kualitas Produk Ddengan Metode Six Sigma pada Harian Tribun Timur : Skripsi, Jurusan Ekonomi Universitas Hasanuddin http://repository.unhas.ac.id/bitstream/handle/123456789/1198/achmad\%20muhaemin\%2 0A21108295\%20\%28full\%29.pdf?sequence=2 29 Maret 2013

[7] Pande, Peter S. Neuman, Robert P. Cavanagh dan Roland R. 2002. The Six Sigma Way. Yogyakarta : Andi Offset

[8] Render, Barry dan Jay Heizer, 2001. Prinsip-Prinsip Manajemen Operasi. Jakarta : Salemba Empat.

[9] Schroeder, G. Roger.1996. Manajemen Operasi. Jakarta : Erlangga.

[10] Setiawan, Hendra. Metode Six Sigma dan Kepuasan Pelanggan: MateriKuliah.com http://titiayem.staff.gunadarma.ac.id/Downloads/files/14253/hendra_six_sigma.pdf Maret 2013

[11] Sumayang, Lalu. 1991. Dasar-Dasar Manajemen Produksi dan Operasi. Jakarta: Salemba Empat 
Tabel 5. Failure Modes and Effect Analysis (FMEA)

\begin{tabular}{|c|c|c|c|c|c|c|c|c|c|c|}
\hline No & $\begin{array}{l}\text { Jenis } \\
\text { Cacat }\end{array}$ & $\begin{array}{l}\text { Component/ } \\
\text { Item or } \\
\text { Prosess }\end{array}$ & $\begin{array}{l}\text { Potential Filure } \\
\text { Mode }\end{array}$ & $\begin{array}{c}\text { Potential Effect or } \\
\text { Failure }\end{array}$ & $S$ & $\begin{array}{l}\text { Potential Cause of } \\
\text { Filure }\end{array}$ & $O$ & Control & $D$ & $R P N$ \\
\hline \multirow[t]{9}{*}{1} & \multirow{9}{*}{$\begin{array}{l}\text { Bocor } \\
\text { Lid }\end{array}$} & \multirow[t]{7}{*}{ Filling Unit } & \multirow{2}{*}{$\begin{array}{l}\text { Heater kurang } \\
\text { Panas }\end{array}$} & \multirow{2}{*}{$\begin{array}{l}\text { Proses pressing lid cup } \\
\text { kurang sempurna }\end{array}$} & \multirow{2}{*}{5} & Listrik sering padam & 3 & \multirow{2}{*}{$\begin{array}{l}\text { Pengecekan suhu pada } \\
\text { heater standar } 180-200{ }^{\circ} \mathrm{C}\end{array}$} & \multirow{2}{*}{2} & \multirow{2}{*}{30} \\
\hline & & & & & & Tegangan listrik kurang & 3 & & & \\
\hline & & & \multirow{2}{*}{ Heater terlalu panas } & Lid bisa sobek & 5 & $\begin{array}{l}\text { Pengaturan suhu tidak } \\
\text { tepat }\end{array}$ & 2 & \multirow{2}{*}{$\begin{array}{l}\text { Pengurangan tegangan } \\
\text { apabila melebihi suhu } \\
\text { standar } 180-200{ }^{\circ} \mathrm{C}\end{array}$} & \multirow{2}{*}{2} & \multirow{2}{*}{20} \\
\hline & & & & $\begin{array}{l}\text { Proses pressing tidak } \\
\text { maksimal }\end{array}$ & 4 & $\begin{array}{l}\text { Suhu melebihi standar } \\
180-200^{\circ} \mathrm{C}\end{array}$ & 2 & & & \\
\hline & & & $\begin{array}{l}\text { Bucket dengan } \\
\text { trimming tidak } \\
\text { center }\end{array}$ & $\begin{array}{l}\text { Pisau pemotong lid } \\
\text { mengenai produk }\end{array}$ & 3 & $\begin{array}{l}\text { Baut pengencang } \\
\text { bucket longgar }\end{array}$ & 3 & $\begin{array}{l}\text { Pengencangan dan } \\
\text { penyetingan ulang pada } \\
\text { bucket }\end{array}$ & 2 & 12 \\
\hline & & & \multirow[b]{2}{*}{ Seal disc kotor } & Lid jadi sobek & 4 & \multirow[b]{2}{*}{$\begin{array}{l}\text { Serbuk lid nempel pada } \\
\text { seal disc }\end{array}$} & \multirow[b]{2}{*}{4} & \multirow{2}{*}{$\begin{array}{l}\text { Pembersihan atau } \\
\text { pengamplasan seal disc } \\
\text { yang kotor }\end{array}$} & \multirow[b]{2}{*}{2} & \multirow[b]{2}{*}{40} \\
\hline & & & & $\begin{array}{l}\text { Proses pressing tidak } \\
\text { maksimal }\end{array}$ & 5 & & & & & \\
\hline & & Material & Bibir cup tidak rata & $\begin{array}{l}\text { Proses pressing tidak } \\
\text { sempurna }\end{array}$ & 3 & $\begin{array}{l}\text { Kualitas bahan baku } \\
\text { dari supplier kurang } \\
\text { baik }\end{array}$ & 2 & $\begin{array}{l}\text { Bibir cup yang tidak rata } \\
\text { dipisahkan dari dispenser }\end{array}$ & 4 & 18 \\
\hline & & Operator & $\begin{array}{l}\text { Operator kurang } \\
\text { cermat }\end{array}$ & $\begin{array}{l}\text { Produk bergesekan } \\
\text { dengan belt conveyor }\end{array}$ & 4 & $\begin{array}{l}\text { Produk menumpuk di } \\
\text { ujung conveyor }\end{array}$ & 4 & $\begin{array}{l}\text { Operator diberitahu } \\
\text { dengan cara ditegur }\end{array}$ & 2 & 32 \\
\hline \multirow[t]{2}{*}{2} & \multirow[t]{2}{*}{$\begin{array}{l}\text { Pecah } \\
\text { Lid }\end{array}$} & Material & Lid getas & $\begin{array}{l}\text { Pinggiran lid pada } \\
\text { bibir cup pecah }\end{array}$ & 3 & $\begin{array}{l}\text { Kualitas lid yang } \\
\text { masuk tidak sesuai } \\
\text { standar }\end{array}$ & 3 & $\begin{array}{l}\text { Penggantian roll lid } \\
\text { dengan yang baru }\end{array}$ & 1 & 9 \\
\hline & & Operator & $\begin{array}{l}\text { Handling kurang } \\
\text { baik }\end{array}$ & $\begin{array}{l}\text { Produk terjatuh } \\
\text { kelantai }\end{array}$ & 3 & $\begin{array}{l}\text { Operator kurang } \\
\text { disiplin dalam } \\
\text { penanganan produk } \\
\end{array}$ & 4 & $\begin{array}{l}\text { Operator diberitahu } \\
\text { dengan cara ditegur }\end{array}$ & 2 & 24 \\
\hline \multirow[t]{2}{*}{3} & \multirow[t]{2}{*}{$\begin{array}{l}\text { Lid } \\
\text { Miring }\end{array}$} & Filling Unit & $\begin{array}{l}\text { Kedudukan roll lid } \\
\text { goyang }\end{array}$ & $\begin{array}{l}\text { Lid goyang saat } \\
\text { pressing }\end{array}$ & 3 & $\begin{array}{l}\text { Baut pengencang } \\
\text { kedudukan roll lid aus }\end{array}$ & 2 & $\begin{array}{l}\text { Penggantian atau rekondisi } \\
\text { komponen yang aus }\end{array}$ & 2 & 12 \\
\hline & & Operator & $\begin{array}{l}\text { Operator kurang } \\
\text { teliti }\end{array}$ & $\begin{array}{l}\text { Lid tidak center } \\
\text { dengan bibir cup }\end{array}$ & 3 & $\begin{array}{l}\text { Pemasangan } \\
\text { Sambungan lid miring }\end{array}$ & 2 & $\begin{array}{l}\text { Operator ditegur dan } \\
\text { penyetingan ulang roll lid }\end{array}$ & 2 & 12 \\
\hline
\end{tabular}


Tabel 6. Usulan Rencana Perbaikan (Recommended Action)

\begin{tabular}{|c|c|c|c|c|c|c|}
\hline Prioritas & $\begin{array}{l}\text { Jenis } \\
\text { Cacat }\end{array}$ & $\begin{array}{l}\text { Component/ } \\
\text { Item or } \\
\text { Prosess } \\
\end{array}$ & $\begin{array}{l}\text { Potential Filure } \\
\text { Mode }\end{array}$ & Potential Cause of Filure & RPN & Recommended Action \\
\hline 1 & $\begin{array}{l}\text { Bocor } \\
\text { Lid }\end{array}$ & Filling Unit & Seal disc kotor & $\begin{array}{l}\text { Serbuk lid nempel pada seal } \\
\text { disc }\end{array}$ & 40 & $\begin{array}{ll}\text { - } & \text { Memeriksa kondisi sealing unit sebelum melakukan proses } \\
\text { produksi } & \\
\text { - } & \text { Setiap satu miggu sekali mengamplas sealing disc yang } \\
\text { permukaan sudah tidak rata }\end{array}$ \\
\hline 2 & $\begin{array}{l}\text { Bocor } \\
\text { Lid }\end{array}$ & Operator & $\begin{array}{l}\text { Operator kurang } \\
\text { cermat }\end{array}$ & $\begin{array}{l}\text { Produk menumpuk di ujung } \\
\text { conveyor }\end{array}$ & 32 & $\begin{array}{l}\text { - Memberikan bimbingan (training) dan teguran kepada operator } \\
\text { agar tidak melakukan kesalahan } \\
\text { - Melakukan inspeksi secara intensif terhadap operator oleh } \\
\text { pengawas }\end{array}$ \\
\hline \multirow[b]{2}{*}{3} & \multirow[b]{2}{*}{$\begin{array}{l}\text { Bocor } \\
\text { Lid }\end{array}$} & \multirow[b]{2}{*}{ Filling Unit } & \multirow[b]{2}{*}{$\begin{array}{l}\text { Heater kurang } \\
\text { Panas }\end{array}$} & Listrik sering padam & \multirow[b]{2}{*}{30} & \multirow{2}{*}{$\begin{array}{l}\text { - Memeriksa kondisi sealing unit sebelum melakukan proses } \\
\text { produksi } \\
\text { - Memeriksa temperatur suhu pada alat indikator sebelum proses } \\
\text { produksi berjalan } \\
\text { - Melakukan inspeksi secara intensif terhadap operator oleh } \\
\text { pengawas }\end{array}$} \\
\hline & & & & Tegangan listrik kurang & & \\
\hline 4 & $\begin{array}{l}\text { Pecah } \\
\text { Lid }\end{array}$ & Operator & $\begin{array}{l}\text { Handling kurang } \\
\text { baik }\end{array}$ & $\begin{array}{l}\text { Operator kurang disiplin } \\
\text { dalam penanganan produk }\end{array}$ & 24 & $\begin{array}{l}\text { - Memberikan bimbingan (training) dan teguran kepada operator } \\
\text { agar tidak melakukan kesalahan } \\
\text { - Melakukan inspeksi secara intensif terhadap operator oleh } \\
\text { pengawas }\end{array}$ \\
\hline 5 & $\begin{array}{l}\text { Bocor } \\
\text { Lid }\end{array}$ & Filling Unit & Heater terlalu panas & $\begin{array}{l}\text { Suhu melebihi standar } \\
180-200{ }^{\circ} \mathrm{C}\end{array}$ & 20 & $\begin{array}{ll}\text { - } & \text { Penyetelan suhu sebelum melakukan proses produksi } \\
\text { - } & \text { Operator secara intensif mengontrol suhu pada seal disk unit }\end{array}$ \\
\hline 6 & $\begin{array}{l}\text { Bocor } \\
\text { Lid }\end{array}$ & Material & Bibir cup tidak rata & $\begin{array}{l}\text { Kualitas bahan baku dari } \\
\text { suplyer kurang baik }\end{array}$ & 18 & $\begin{array}{l}\text { - Pemisahan cup yang tidak standart sebelum dimasukkan kedalam } \\
\text { dispencer }\end{array}$ \\
\hline 7 & $\begin{array}{l}\text { Bocor } \\
\text { Lid }\end{array}$ & Filling Unit & $\begin{array}{l}\text { Bucket dengan } \\
\text { trimming tidak } \\
\text { center }\end{array}$ & $\begin{array}{l}\text { Baut pengencang bucket } \\
\text { longgar }\end{array}$ & 12 & $\begin{array}{ll}\text { - } & \text { Memeriksa kondisi mesin sebelum melakukan proses produksi } \\
\text { - } & \text { Melakukan pengencangan baut dan penyetelan diantaranya } \\
\text { - } & \text { bucket dan trimming agar center } \\
\text { - } & \text { Melakukan penggantian baut apabila mengalami aus } \\
& \text { pengawan inspeksi secara intensif terhadap operator oleh } \\
& \text { pelum proses produksi }\end{array}$ \\
\hline 8 & $\begin{array}{l}\text { Lid } \\
\text { Miring }\end{array}$ & Filling Unit & $\begin{array}{l}\text { Kedudukan roll lid } \\
\text { goyang }\end{array}$ & $\begin{array}{l}\text { Baut pengencang kedudukan } \\
\text { roll lid aus }\end{array}$ & 12 & $\begin{array}{ll}\text { - } & \text { Memeriksa kondisi kedudukan roll lid sebelum melakuakn proses } \\
\text { - } & \text { Memberikan bimbingan (training) dan teguran kepada operator } \\
& \text { agar tidak melakukan kesalahan } \\
\text { - } & \text { Melakukan inspeksi secara intensif terhadap operator oleh } \\
& \text { pengawas } \\
\text { - } & \text { Pemberian pelumas khusus industri secara teratur }\end{array}$ \\
\hline
\end{tabular}




\begin{tabular}{|c|l|l|l|l|l|l|}
\hline & & & & & $\begin{array}{l}\text { Penggantian komponen jika life time sudah habis sesuai dengan } \\
\text { ketentuan }\end{array}$ \\
\hline & & & & & $\begin{array}{l}\text { Pemasangan sambungan lid dengan benar sebelum mesin kembali } \\
\text { dijalankan } \\
\text { Memberikan bimbingan (training) dan teguran kepada operator } \\
\text { agar tidak melakukan kesalahan } \\
\text { Melakukan inspeksi secara intensif terhadap operator oleh } \\
\text { pengawas }\end{array}$ \\
\hline 10 & $\begin{array}{l}\text { Miring } \\
\text { Lid }\end{array}$ & Operator & $\begin{array}{l}\text { Operator kurang } \\
\text { teliti }\end{array}$ & $\begin{array}{l}\text { Pemasangan Sambungan lid } \\
\text { miring }\end{array}$ & 12 & \begin{tabular}{l} 
Tidak ada \\
\hline
\end{tabular} \\
\hline
\end{tabular}

